\section{(6) OPEN ACCESS}

\title{
Characterisation of liver pathogenesis, human immune responses and drug testing in a humanised mouse model of HCV infection
}

\author{
Choong Tat Keng, ${ }^{1}$ Ching Wooen Sze, ${ }^{2}$ Dahai Zheng, ${ }^{1}$ Zhiqiang Zheng, ${ }^{1}$ \\ Kylie Su Mei Yong, ${ }^{1}$ Shu Qi Tan, ${ }^{3}$ Jessica Jie Ying Ong, ${ }^{1}$ Sue Yee Tan, ${ }^{1}$ Eva Loh, ${ }^{4}$ \\ Megha Haridas Upadya, ${ }^{2}$ Chik Hong Kuick, ${ }^{4}$ Hak Hotta, ${ }^{5}$ Seng Gee Lim, 6,7 \\ Thiam Chye Tan, ${ }^{3,8}$ Kenneth T E Chang, ${ }^{4,8}$ Wanjin Hong, ${ }^{1}$ Jianzhu Chen, ${ }^{9,10}$ \\ Yee-Joo Tan, ${ }^{1,2}$ Qingfeng Chen ${ }^{1,2,9}$
}

\begin{abstract}
- Additional material is published online only. To view please visit the journal online (http://dx.doi.org/10.1136/ gutjnl-2014-307856).

For numbered affiliations see end of article.
\end{abstract}

\section{Correspondence to} Dr Qingfeng Chen, Institute of Molecular and Cell Biology, Proteos, 61 Biopolis Drive, Singapore 138673, Singapore; qchen@imcb.a-star.edu.sg Dr Yee-Joo Tan, Department of Microbiology, MD4, Level 3, 5 Science Drive 2, National University of Singapore, Singapore 117597, Singapore; yee_joo_tan@nuhs.edu.sg

Received 15 June 2014 Revised 9 May 2015 Accepted 11 May 2015 Published Online First 6 July 2015

\section{ABSTRACT}

Objective HCV infection affects millions of people worldwide, and many patients develop chronic infection leading to liver cancers. For decades, the lack of a small animal model that can recapitulate HCV infection, its immunopathogenesis and disease progression has impeded the development of an effective vaccine and therapeutics. We aim to provide a humanised mouse model for the understanding of HCV-specific human immune responses and HCV-associated disease pathologies.

Design Recently, we have established human liver cells with a matched human immune system in NOD-scid $1 / 2 \mathrm{rg}^{-/-}$(NSG) mice (HIL mice). These mice are infected with HCV by intravenous injection, and the pathologies are investigated.

Results In this study, we demonstrate that HIL mouse is capable of supporting HCV infection and can present some of the clinical symptoms found in HCV-infected patients including hepatitis, robust virus-specific human immune cell and cytokine responses as well as liver fibrosis and cirrhosis. Similar to results obtained from the analysis of patient samples, the human immune cells, particularly $\mathrm{T}$ cells and macrophages, play critical roles during the HCV-associated liver disease development in the HIL mice. Furthermore, our model is demonstrated to be able to reproduce the therapeutic effects of human interferon alpha 2a antiviral treatment.

Conclusions The HIL mouse provides a model for the understanding of HCV-specific human immune responses and HCV-associated disease pathologies. It could also serve as a platform for antifibrosis and immunemodulatory drug testing.

\section{Significance of this study}

What is already known on this subject?

- Small animal models for HCV study are important and urgently needed to study HCV infection, immune responses and pathogenesis.

- Although immunodeficient mice supplemented with human adult hepatocytes support HCV infection, these mice lack a human immune system.

- So far human immune responses have not been well-characterised in the existing mouse models for HCV.

\section{What are the new findings?}

- We have developed a simple method to establish human liver and immune systems in NOD-scid $/ 12 \mathrm{rg}^{-/-}$mouse that support HCV infection and associated disease development.

- Our results suggest that the human immune system in our mouse model plays critical roles in controlling the HCV-induced liver disease progression.

- Our HCV model can reproduce the therapeutic effects of some anti-HCV drugs used in clinic.

How might it impact on clinical practice in the foreseeable future?

- The small animal model reported here likely will facilitate the dissection of human immune responses to hepatitis virus infection and the evaluation of therapeutics and vaccines.
CrossMark

To cite: Keng CT, Sze CW, Zheng $\mathrm{D}$, et al. Gut 2016;65:1744-1753.

\section{INTRODUCTION}

With $>175$ million people infected globally, the HCV represents a major health concern worldwide. ${ }^{1}$ Many of these patients with the infection often progress to develop hepatitis, liver fibrosis, cirrhosis and hepatocellular adenoma or carcinoma. $^{2}$ A major obstacle in the development of vaccine and antiviral therapy arises from the fact that HCV tropism is restricted to humans. Chimpanzees are currently the most complete model that can support the complete HCV life cycle and recapitulate the host responses observed in human patients, but limitations such as low chronic infection rate, poor demonstration of liver fibrosis, high cost and ethical concerns have limited their usage for HCV research. ${ }^{3} 4$

The lack of a small animal model that can recapitulate the viral infection and liver pathogenesis observed in human patients has limited progress in the understanding of the viral-host interactions, $\mathrm{HCV}$-specific immune responses and progression of 
the diseased pathology as well as in the development of vaccines and therapeutics. ${ }^{5}$ The current mouse models for HCV infection are mostly transgenic mouse models that were genetically modified to allow virus infection to mouse hepatocytes or to enhance the transplantation of mature human hepatocytes. ${ }^{7-10}$ The immunodeficient Alb-uPA/SCID mouse with the repopulation of mature human hepatocytes was the first mouse model to demonstrate successful $\mathrm{HCV}$ infection and replication in vivo. ${ }^{9}$ The Fah-Rag2- $\mathrm{\gamma C}$ null mice were later developed to solve some of the limitations of the Alb-uPA/SCID mice such as the fragility or excessive mortality of the mice. ${ }^{11}$ These mouse models can be efficiently infected with HCV but did not develop clinical symptoms seen in $\mathrm{HCV}$-infected patients. ${ }^{12-14}$

Recently, the AFC8-HSC/Hep Balb/C Rag2- $\gamma \mathrm{C}$-null and HLA-A2 NOD-scid Il2 $\mathrm{rg}^{-/-}$(NSG) mouse models were developed with both human immune system and liver cells. ${ }^{15} 16$ The transplantation of liver progenitor cells in this transgenic mouse requires extra treatment to induce liver cell death. Both mouse models were shown to be able to support hepatitis virus infection with liver inflammation, hepatitis and fibrosis. Previously, we demonstrated a simple one-step engraftment of human liver cells and a matching human immune system in the same NSG mouse (HIL mice), without the need for transgenic modification or drug treatment. ${ }^{17}$ In this study, we showed that the HIL mice can support HCV infection, liver inflammation, HCV-specific human immune responses, as well as liver fibrosis. Antiviral treatment using interferon alpha-2a (IFN $\alpha-2 a)$ was able to block the progression of the $\mathrm{HCV}$-associated liver pathogenesis.

\section{METHODS}

\section{Human fetal liver progenitor stem cells}

Human CD34+ cells were freshly isolated from aborted fetuses at 15-23 weeks of gestation, in accordance with the institutional ethical guidelines of the KK Women's and Children's Hospital, Singapore. Fetal liver tissues were processed as described previously. ${ }^{17} \mathrm{CD} 34+$ cells were purified by magnetic-activated cell sorting using the EasySep CD34-positive selection kit (Stemcell Technologies) under sterile conditions, following manufacturer's protocol. The purity of the CD34+ cells was 90-99\%.

More detailed materials and methods can be found in online supplementary material.

\section{RESULTS \\ HCV infection leads to liver leucocyte infiltration and lesions in HIL mice}

Good human immune cell reconstitution with a mean of $~ 40 \%$ was reproducibly obtained for HIL mice (see online supplementary figure S1A and S1B). Five to ten per cent of hepatocytes were stained positive for human albumin (hALB) in HIL mouse livers while no staining was observed in NSG mice (see online supplementary figure S1C). Eight-week-old HIL mice have serum hALB levels with a mean value of $26.4 \mathrm{ng} / \mathrm{mL}$ (see online supplementary figure S1D). To analyse the maturation status of human hepatocytes in HIL mice, human epidermal growth factor receptor ${ }^{+}\left(\mathrm{hEGFR}^{+}\right)$cells were purified from perfused livers and assayed for hepatocyte markers. Similar to human adult hepatocytes, these $\mathrm{hEGFR}^{+}$cells have high mRNA levels of human hepatocyte maturation markers like keratin 18 (CK18), tyrosine aminotransferase (TAT), alpha-1 antitrypsin, tryptophan 2,3-dioxygenase and cytochrome P450 (see online supplementary figure S1E). The immunofluorescent staining confirmed that $>95 \%$ of $\mathrm{hEGFR}^{+}$cells expressed hALB, yet only $\sim 50 \%$ of $\mathrm{hEGFR}^{+}$cells expressed the maturation markers CK18 and TAT (see online supplementary figure S1F).
To confirm that the purified hEGFR ${ }^{+}$cells accurately represent all human hepatocytes in livers of HIL mice, liver sections were stained with antibodies specific against hALB or hEGFR. Coexpression of hALB and hEGFR could be seen in $>95 \%$ of hepatocytes that expressed either hALB or hEGFR (see online supplementary figure S1G). Collectively, these results show the presence of mature human hepatocytes in HIL mice and that hEGFR can be used effectively as a marker for sorting out human hepatocytes from HIL mice.

Ten-week-old HIL mice were inoculated with $1 \times 10^{6} \mathrm{FFU} / \mathrm{mL}$ of J6/JFH-1 HCV (genotype 2a) viruses. Although we could not detect HCV RNA directly from the sera or livers of HCV-infected HIL mice as they were below our detection limit, we detected HCV RNA in the $\mathrm{hEGFR}^{+}$cells isolated from HCV-infected HIL mice, while no HCV RNA was detected in the $\mathrm{hEGFR}^{+}$cells from mock-infected mice. An average of 321 HCV RNA copies per 100 ng of total RNA was detected in the infected mice 2 weeks post-infection (figure 1A). For the 5 weeks post-infection group, the level of virus appears to have increased as an average of $944.2 \mathrm{HCV}$ RNA copies per $100 \mathrm{ng}$ of total RNA was detected in the infected mice (figure 1A). However, the difference between 2 and 5 weeks is not statistically significant, and there is substantial variation in the HCV RNA levels between mice, thus further studies are needed to determine the temporal expression of viral RNA during the infection cycle in infected HIL mice. Consistently, HCV proteins were detected in the enriched hEGFR hepatocytes using HCV-infected patient serum in both $\mathrm{TAT}^{+}$mature and $\mathrm{TAT}^{-}$ immature cells (see online supplementary figure S2A). Previous studies also showed that HCV could infect immature hepatocytes or induced pluripotent stem cells-derived hepatocyte-like cells that resemble fetal hepatocytes more than adult hepatocytes as they expressed all the necessary HCV entry factors. ${ }^{18-20}$ More importantly, dsRNA was detected only in the CK18 ${ }^{+}$ mature hepatocytes using immunofluorescence, further confirming that active viral replication occurred in the liver of HCV-infected HIL mice (figure 1B). In addition, HCV core antigen was detected in situ in $\sim 10 \%$ of hALB ${ }^{+}$hepatocytes in the liver of HCV-infected HIL mice but not in the mockinfected mice (figure 1C). All these results show that HCV can infect and replicate in the human hepatocytes of HIL mice.

In the livers of HIL mice that were infected with HCV for 0 , $1,3,5$ or 9 weeks, increasing leucocyte infiltration and progressive lesions formation were observed over the course of infection (figure 1D). There was no infiltration or lesions found in the livers of mock-infected HIL mice. At the early stage of infection ( $<6$ weeks), the infiltrated areas of human CD45 + cells correlated well with areas positive for hALB, suggesting the target of initial leucocyte infiltration is human hepatocytes (see online supplementary figure S2B). As only $\sim 10 \%$ of the $\mathrm{hALB}^{+}$cells were infected with $\mathrm{HCV}$, it seems like leucocyte infiltration has also occurred rapidly in the surrounding bystander cells. Consistent with the progressive liver damage observed in H\&E staining, serum alanine aminotransferase (ALT) level were also elevated in HIL mice over the course of HCV infection (figure 1E). Overall, HIL mice are able to support HCV infection that leads to immune cell infiltration and progressive liver damage.

\section{HCV infection of HIL mice leads to activation of hepatic stellate cells and upregulation of fibrotic genes with consequential liver fibrosis and cirrhosis}

To study the progression of liver pathology, the livers of mockinfected and HCV-infected HIL mice were harvested at week 0-9 post-infection for histological examination. In the livers, 
Figure 1 HCV can infect HIL mice leading to liver inflammation and liver injury. (A and B) Ten-week-old HIL mice were mock-infected or HCV-infected. (A) Human epidermal growth factor receptor ${ }^{+}\left(\mathrm{hEGFR}^{+}\right.$) cells were purified from mouse livers at 2 and 5 weeks post-infection and analysed for HCV RNA by RT-PCR ( $\mathrm{n} \geq 5$ mice per group). In one group of mice, HCV infection was performed with $\mathrm{T}$ cell depletion and analysis was performed at 5 weeks post-infection (indicated by \#). Values from each mouse are plotted as symbols, and the average values for each group are plotted as solid lines. (B) Staining of dsRNA (in red) and CK18 (in green) in the hEGFR ${ }^{+}$cells purified from HIL mice at 2 and 5 weeks post-infection. (C) Livers were harvested and paraffin sections were prepared 5 weeks post-HCV infection ( $n=5$ mice per group). Representative stains for DAPI (blue), anti-HCV core (green) and antihuman albumin (hALB) (red) are shown. (D and E) Ten-week-old HIL mice were infected with $\mathrm{HCV}$ or mock-infected for $0,1,3,5$ and 9 weeks ( $n=5$ mice per group). Livers and sera were harvested for histology and alanine aminotransferase (ALT) assay. (D) Representative liver $\mathrm{H} \& \mathrm{E}$ stains of mock-infected and $\mathrm{HCV}$-infected mice from different time points are shown. (E) Serum ALT levels in HIL mice that were mock-infected or HCV-infected from different time points are represented. Data represent mean \pm SEM.
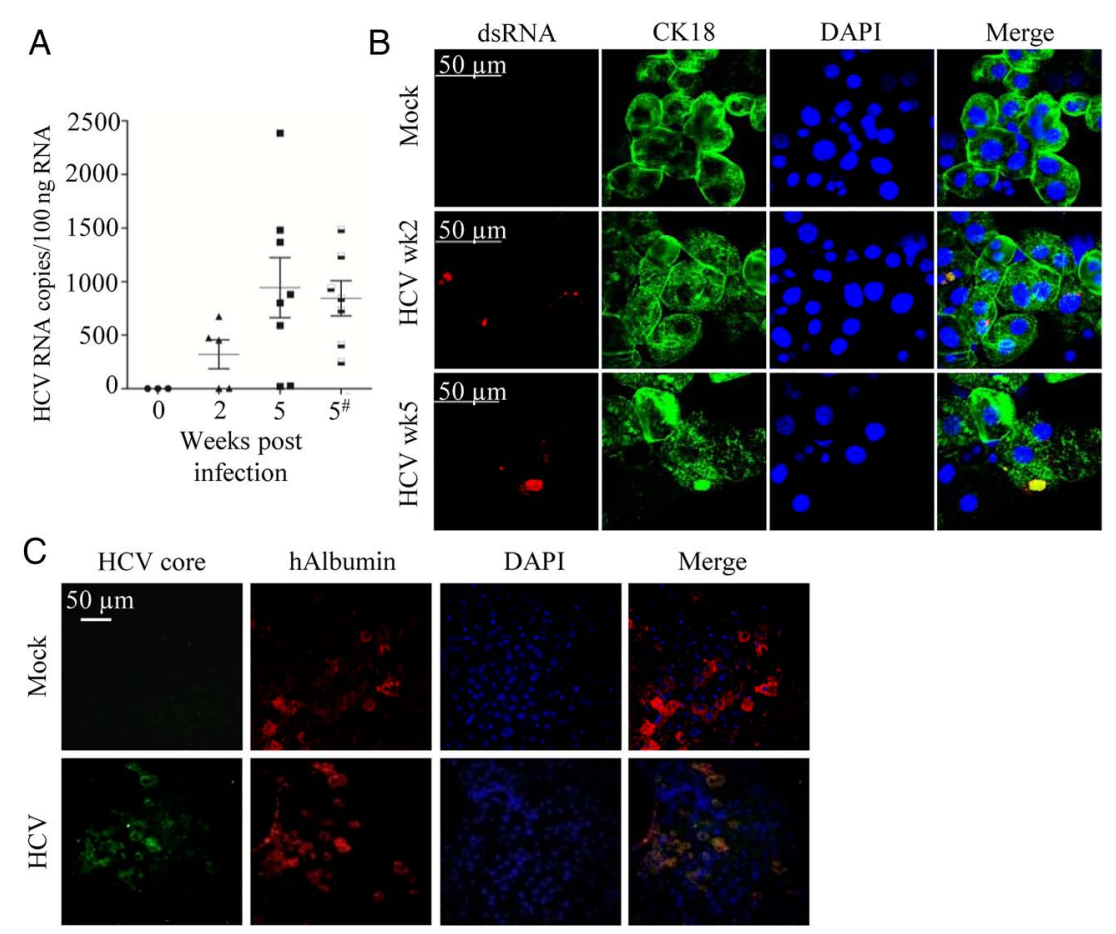

Merge

D

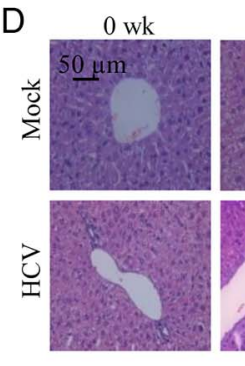

$1 \mathrm{wk}$
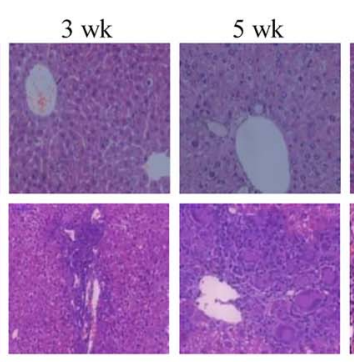

9 wk

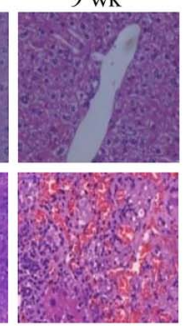

E

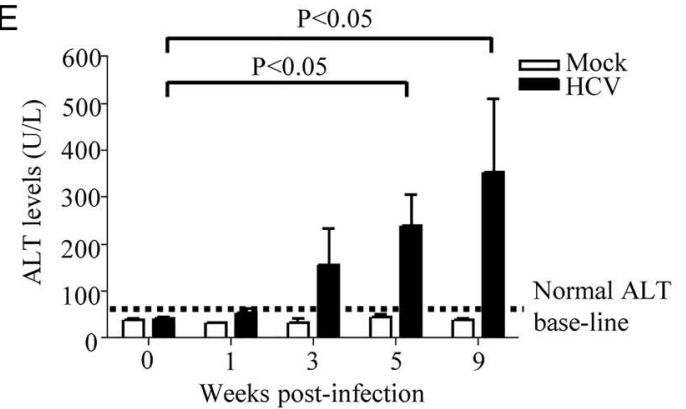

there were nodule fibrosis at 3 weeks post-infection, fibrosis with numerous septa at 5 weeks post-infection and severe scarring and cirrhosis with nodular structures forming as a result of inflammation at 9 weeks post-infection (figure $2 \mathrm{~A}$ and see online supplementary figure S3A). No liver pathology was observed in the mock-infected HIL mice (figure 2A). A representative list of HCV-infected or mock-infected HIL mice with their respective liver disease scoring is provided in online supplementary table S1. Further analysis showed that there was no inflammation or lesions in other organs (lung, kidney, heart and intestines) of mock-infected or HCV-infected HIL mice, indicating that the pathology observed in the HCV-infected HIL mice is liver-specific (see online supplementary figure S3B). In addition, there is no cell infiltration or damage in HCV-infected $\mathrm{Balb} / \mathrm{c}$ and NSG mice, which do not have human cells (see online supplementary figure S3C). We previously showed that NSG mice engrafted with human cord blood CD34+ cells
(CB mice) developed human immune system but had few human hepatocytes. ${ }^{17} \mathrm{HCV}$ infection of $\mathrm{CB}$ mice did not result in liver infiltration and lesions (see online supplementary figure S3C), suggesting that both the human immune system and hepatocytes are required to recapitulate the liver pathogenesis observed in HCV-infected patients.

$\mathrm{HCV}$ infection in humans is known to lead to the activation of hepatic stellate cells, which contributes towards the progression of fibrosis. ${ }^{21}$ As shown by the expression of alpha smooth muscle actin, activation of hepatic stellate cells occurred in $\mathrm{HCV}$-infected but not in mock-infected HIL mice (figure 2B). Gene expressions of collagen 1A1 (Col1A1) and tissue inhibitor of matrix metalloproteinases 1 (TIMP1) are known to be elevated in activated hepatic stellate cells for attenuation of liver fibrosis. ${ }^{22}$ Consistently, the expression of both human and mouse Col1A1 and TIMP1 genes were upregulated in the livers of the HCV-infected HIL mice (figure 2C, D). In addition, high 
Figure 2 HCV-infected HIL mice develop liver fibrosis. (A and $B$ ) Ten-week-old HIL mice were infected with HCV or mock-infected for $0,1,3$, 5 and 9 weeks ( $n=10$ mice per group). Livers were harvested and paraffin sections were prepared. (A) Representative stains for Sirius red/Fast green from different time points are shown. (B) Representative stains of liver sections from HIL mice that were mock-infected or 9 weeks HCV-infected for alpha smooth muscle actin (green) and DAPI (blue) are shown. (C and D) Total liver RNAs were prepared from mock-infected and 9 weeks HCV-infected HIL mice ( $n=3$ mice per group). Relative gene expression levels of human tissue inhibitor of matrix metalloproteinases 1 (TIMP1) and collagen $1 \mathrm{~A} 1$ (Col1A1) $(\mathrm{C})$, and mouse TIMP1 and Col1A1 (D) were represented in the graphs. (E) Serum levels of protein TIMP1 and TIMP2 from mock-infected and 9 weeks HCV-infected HIL mice are represented in the graph. Data represent mean \pm SEM.
A

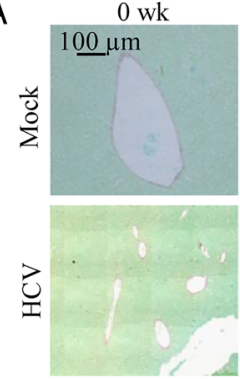

$1 \mathrm{wk}$

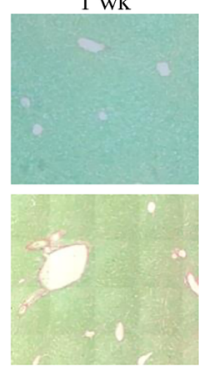

$3 \mathrm{wk}$

$5 \mathrm{wk}$ 9 wk

B

Alpha-smooth muscle actin Mock
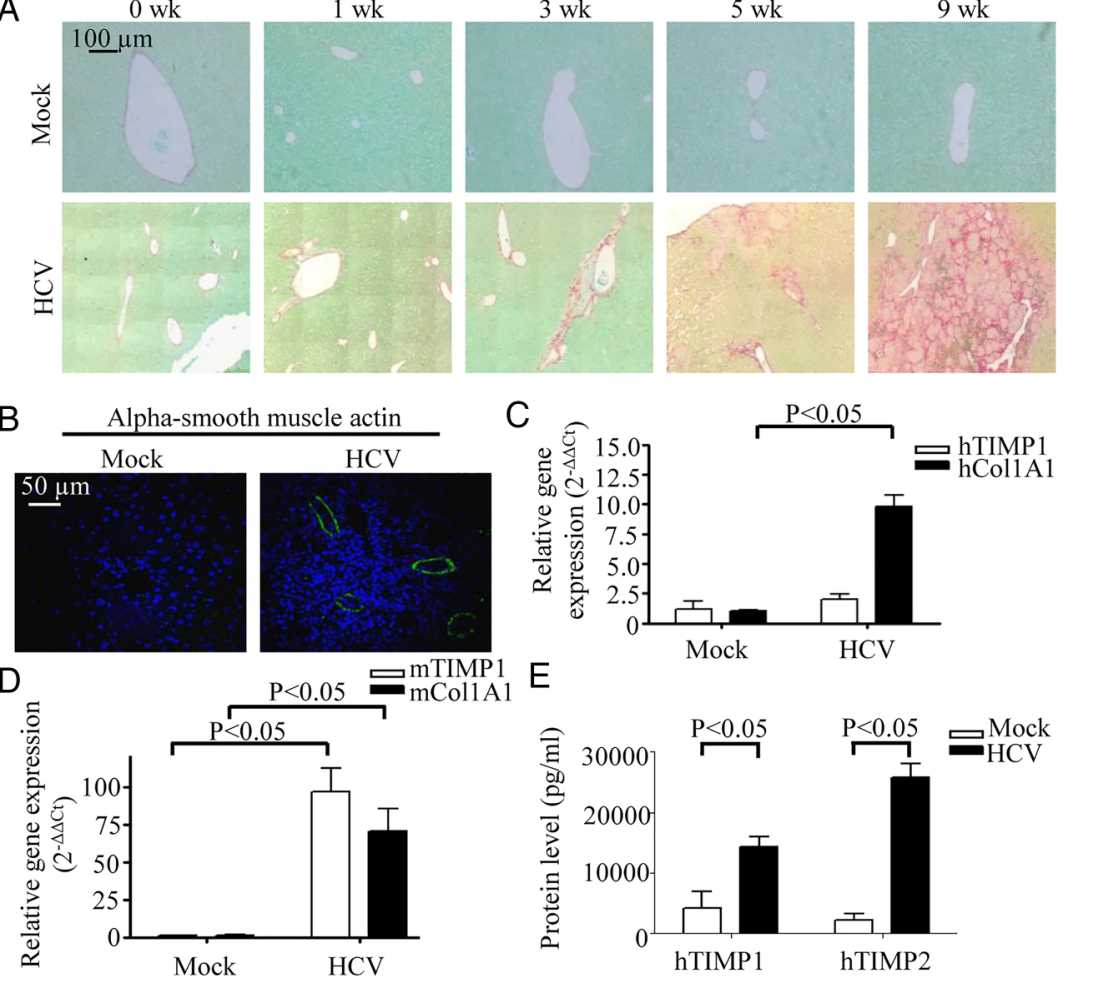

levels of human TIMP1 and TIMP2 proteins were detected in the sera of the HCV-infected mice (figure 2E). These results show that the liver fibrosis and cirrhosis in the chimeric liver of HCV-infected HIL mice resulted from activation of hepatic stellate cells and upregulation of both human and mouse fibrogenic genes.

\section{HCV infection induces intrahepatic human immune cell infiltration and cytokine responses in HIL mice}

To dissect the intrahepatic immune cells infiltration, absolute cell number counts of hepatic mononuclear cells and flow cytometry quantitative analysis were performed. There was a slight increase in human CD45 + leucocytes in the livers of $\mathrm{HCV}$-infected HIL mice at 3-7 weeks post-infection, while the increase at 9 weeks post-infection was almost threefold (figure $3 \mathrm{~A})$. There was no significant cell number change in the mockinfected mice (figure $3 \mathrm{~A}$ ). Among these infiltrated human leucocytes, hepatic human T cells $(\mathrm{CD} 45+\mathrm{CD} 3+$ ) (figure 3B, C) and macrophages (CD45+CD14+) (figure 3B, D) increased most significantly, which is consistent with the observations in $\mathrm{HCV}$-infected patients. ${ }^{23}$ The kinetics of human cell infiltration was correlated with the development and severity of liver damage (figure 1D), fibrosis and cirrhosis (figure 2A), suggesting that the human immune system is involved in the disease development. To assay human cytokine responses to HCV infection in HIL mice, serum human IFN $\gamma$ and interleukin (IL)6 levels were monitored over the course of infection. Both human IFN $\gamma$ (figure 3E) and IL-6 (figure 3F) levels increased gradually over the course of infection reaching an average of $440 \pm 181$ and $234 \pm 109 \mathrm{pg} / \mathrm{mL}$, respectively, at 9 weeks post-infection. In contrast, human IFN $\gamma$ and IL-6 levels were barely detectable in $\mathrm{HCV}$-infected $\mathrm{CB}$ mice (see online supplementary figure S3D and S3E). These results show that human immune system in HIL mice are able to generate robust human cellular and cytokine responses to $\mathrm{HCV}$ infection.
The human inflammatory cytokine profiles in HCV-infected HIL mice are similar to human

To analyse the inflammatory human cytokine profiles in the HCV-infected HIL mouse model, sera from HIL mice were assayed for another 28 inflammatory cytokines. At 9 weeks postinfection, 10 cytokines showed elevated levels in the sera of HCV-infected HIL mice (figure 3G), while 7 of them (B lymphocyte chemoattractant (BLC), eosinophil chemotactic protein 2, I-309, IL-8, monocyte chemotactic protein-1 (MCP1), monocyte chemotactic protein-1 beta (MIP1b) and tumour necrosis factor receptor II (TNF-RII)] were significantly upregulated. Consistently, BLC, ${ }^{24} \mathrm{IL}-8,{ }^{25} \mathrm{MCP} 1,{ }^{26} \mathrm{MIP}^{25} \mathrm{~b}^{27} 28$ and TNF-RII ${ }^{29}$ were also found to be upregulated in $\mathrm{HCV}$-infected patients. These results show that the proinflammatory human cytokine responses in $\mathrm{HCV}$-infected HIL mice are similar to those in infected humans.

\section{HCV infection elicits robust virus-specific immune cell responses in HIL mice}

To investigate the presence of $\mathrm{HCV}$-specific human immune responses in HIL mice, splenocytes from HCV-infected and mock-infected HIL mice at 9 weeks post-infection were analysed. A drastic increase of the spleen size (figure 4A) and splenocyte numbers was observed in HCV-infected HIL mice with a mean of $4.48 \times 10^{8}$ cells compared with $6.5 \times 10^{7}$ cells in mockinfected mice (figure 4B). In the mock-infected HIL mice, the majority of the human leucocytes in spleen were CD19+ B cells with a mean of $71.0 \%$, while CD3 $+\mathrm{CD} 4+$ and $\mathrm{CD} 3+\mathrm{CD} 8+\mathrm{T}$ cells were represented by a mean of $6.1 \%$ and $6.2 \%$, respectively (figure 4C, left). In HCV-infected mice, human CD3 $+\mathrm{CD} 4+$ and $\mathrm{CD} 3+\mathrm{CD} 8+\mathrm{T}$ cells expanded and became pre(figure $4 \mathrm{C}$, right). In terms of total cell number, there was a significant increase of $\sim 58$-fold in $\mathrm{CD} 3+\mathrm{CD} 4+\mathrm{T}$ cells and $\sim 19$-fold in CD3 +CD8 $+\mathrm{T}$ cells in $\mathrm{HCV}$-infected HIL mice (figure 4D). A relatively smaller increase of approximately 
Figure 3 HCV infection leads to intrahepatic human $\mathrm{T}$ cell and macrophage infiltration and cytokine responses. (A to D) Total intrahepatic mononuclear cells (MNCs) were isolated from HIL mice that were mock-infected or HCV-infected for 0,1 , $3,5,7$ and 9 weeks ( $n=5$ mice per group). Data represent mean \pm SEM. (A) The numbers of human CD45+ cells were determined from the percentages of CD45+ cells among total hepatic MNCs and the absolute cell number count. (B) MNCs from livers of 9 weeks mock-infected and HCV-infected mice were stained for human CD3 and human CD14. Shown are representative plots of Forward-scattered light (FSC) versus hCD3 or hCD14. ( $n=5$ mice per group). (C) The numbers of human CD45+ CD3 $+T$ cells were determined from the percentages of CD45+CD3+ cells among total hepatic MNCs and the absolute cell number count. (D) The number of CD45+CD14+ cells was determined from the percentage of CD45+CD14+ macrophages among total hepatic MNCs and the absolute cell number count. ( $E$ and F) Sera were prepared from HIL mice that were infected for 0, 1, 3, 5, 7 and 9 weeks and analysed for human interferon (IFN) $\gamma$ and interleukin (IL)-6 by ELISA ( $n=5$ mice per group). (E) Serum levels of human IFN $\gamma$. (F) Serum levels of human IL-6. Data represent mean \pm SEM. (G) HCV infection results in the elevated serum levels of inflammatory human cytokines in HIL mice. Serum levels of human B lymphocyte chemoattractant (BLC), eosinophil chemotactic protein 2 (Eotaxin-2), I-309, IL-8, IL-16, IL-17, monocyte chemotactic protein-1 (MCP1), MCSF, monocyte chemotactic protein-1 beta (MIP1b) and tumour necrosis factor receptor II (TNF-RII) of 9 weeks mock-infected and HCV-infected HIL mice were determined by the human inflammatory cytokine array $(n=5)$. Data represent mean \pm SEM.
A
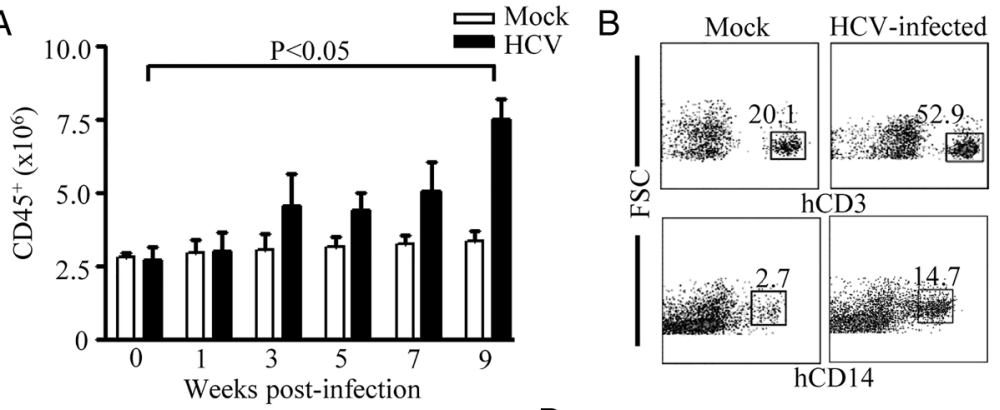

\section{C}
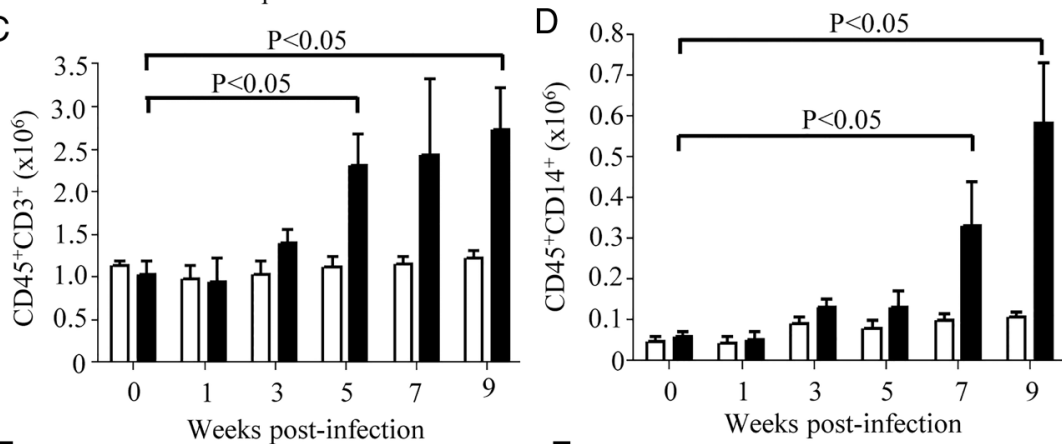

E

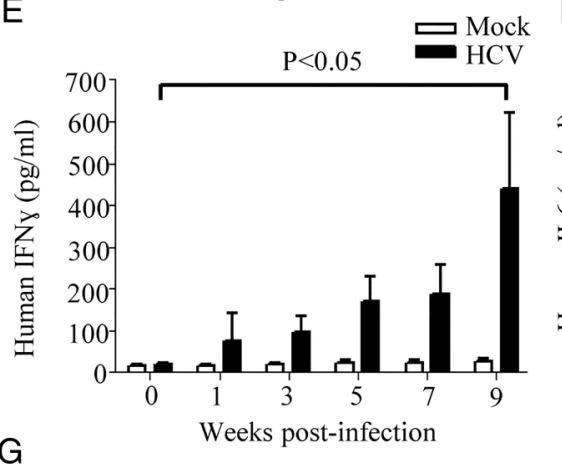

F
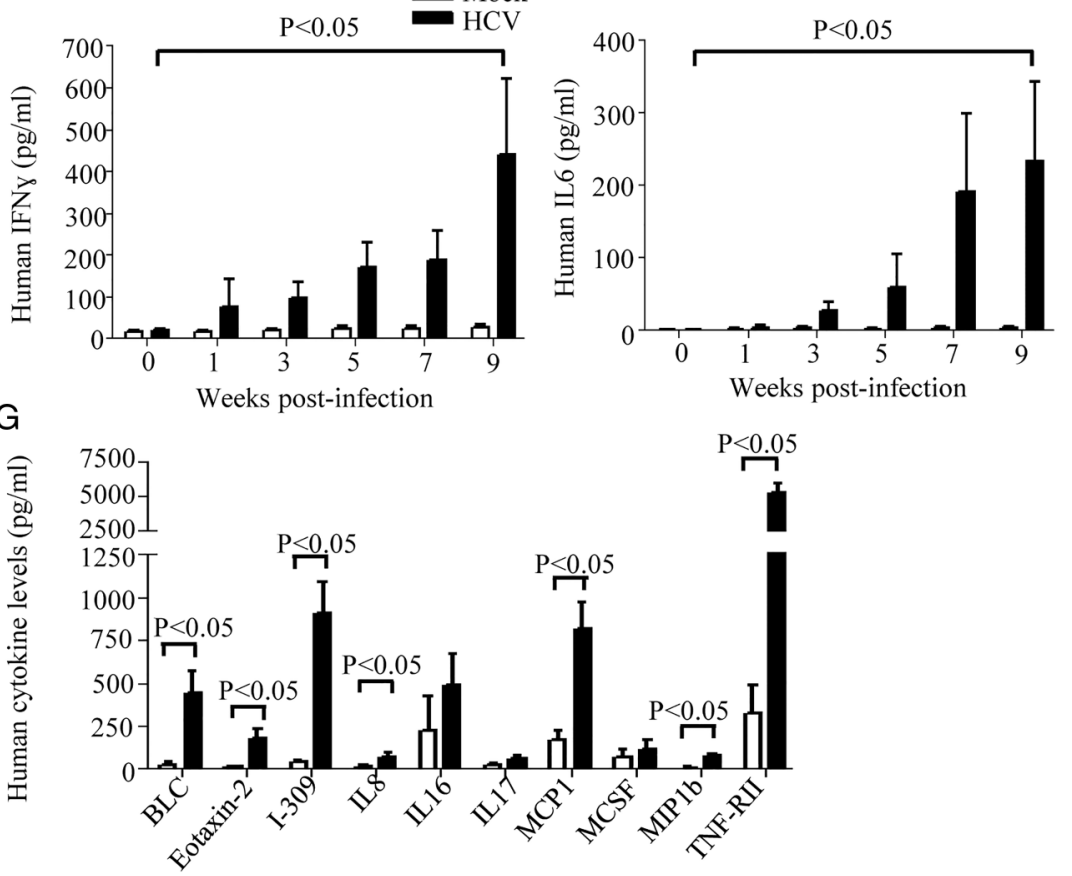

twofold in CD19+ B cells, CD56+ natural killer cells and CD14+ macrophages were observed (figure 4D). These data suggest that CD4+ and CD8 $+\mathrm{T}$ cell responses are predominant in HIL mice during $\mathrm{HCV}$ infection, which is consistent to human.

To test the levels of human HCV-specific T cell responses, splenocytes from HCV-infected and mock-infected HIL mice were used for human IFN $\gamma$ ELISPOT assay. Splenocytes were stimulated with a mixture of 16 synthetic overlapping peptides covering the HCV core protein or SARS synthetic peptides, which served as a non-specific stimulation control. Phorbol 12-myristate 13-acetate (PMA) and ionomycin stimulation served as positive control. For splenocytes from $\mathrm{HCV}$-infected HIL mice, the numbers of IFN $\gamma$-producing spots forming units were detected at a mean of 1400 /million cells in HCV peptidestimulated group, which is significantly higher than the SARS peptide-stimulated group or non-stimulated group (figure 4E). Splenocytes from mock-infected mice did not respond to the peptide stimulations (figure 4E). This result demonstrates that robust HCV-specific $\mathrm{T}$ cell responses are present in HCV-infected HIL mice.

Sera from HCV-infected HIL mice were tested for the presence of anti-HCV human antibodies by immunofluorescence and ELISA. HCV-specific human IgG was detected in the sera from $\sim 20 \%$ of HCV-infected HIL mice by staining HCV-infected Huh7.5 cells (see online supplementary figure S4A). Uninfected Huh7.5 cells were stained negative using the same sera. ELISA also showed that there were specific anti-HCV 
A

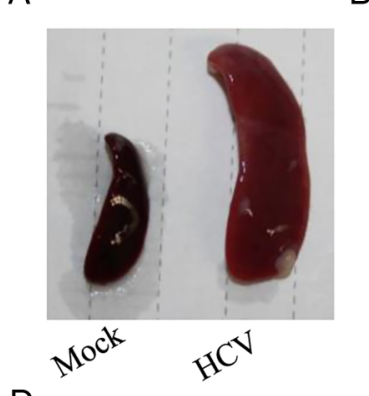

$\mathrm{B}$

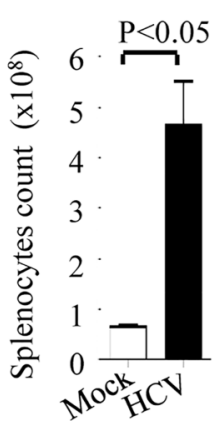

C
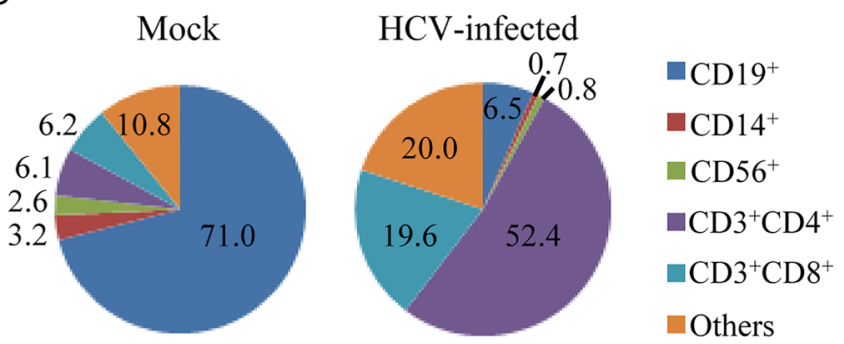

$\mathrm{D}$

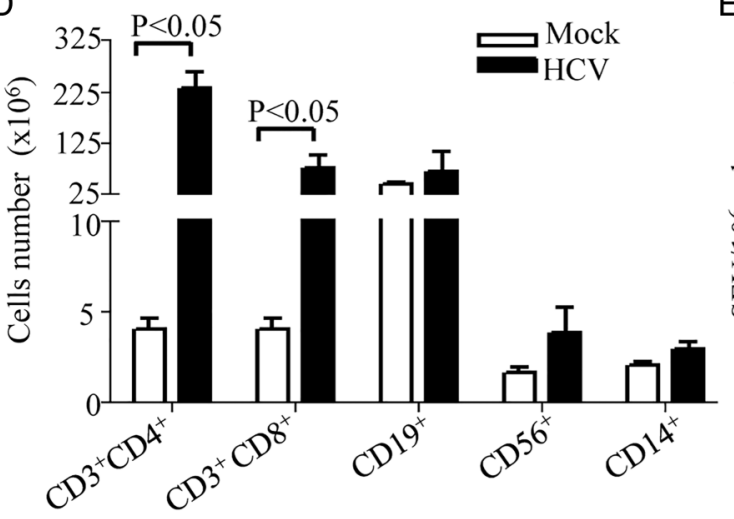

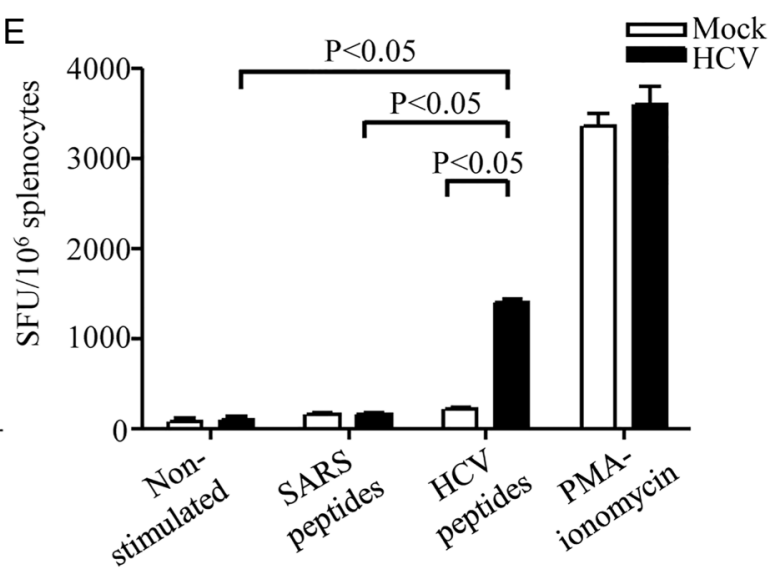

Figure 4 HCV infection induces HCV-specific human T cell response in HIL mice. HIL mice were mock-infected or HCV-infected for 9 weeks $(n=4$ mice per group). (A) Representative images showing gross appearance of spleen obtained from mock-infected or HCV-infected HIL mice. (B) The number of splenocytes in the mock-infected and HCV-infected HIL mice were counted and represented in the graph. (C) Graph representing the different immune cell populations in the splenocytes of mock-infected and HCV-infected HIL mice. Numbers are in percentages. (D) The total number of each immune cell types in mock-infected and HCV-infected HIL mice is represented in the graph. (E) Spleen mononuclear cells (MNCs) were isolated and $1 \times 10^{5}$ MNCs were used for stimulation with 1620 -mer HCV core peptides for $24 \mathrm{~h}$ for human interferon (IFN) $\gamma$ ELISPOT assay. Representative ELISPOT results for non-stimulated (Ctrl), SARS peptides-stimulated and HCV peptides-stimulated MNCs from mock-infected and HCV-infected mice are shown. Phorbol myristate acetate (PMA)-ionomycin stimulated cells were used as positive control. The human IFN $\gamma$ T cell responses from each group are shown as spots forming units per $10^{6} \mathrm{MNCs}$. Data represent mean \pm SEM.

NS3 antibodies in the sera of HCV-infected HIL mice (see online supplementary figure S4B). This result indicates the presence of HCV-specific human antibody responses in the HCV-infected HIL mice.

Human T cells and macrophages play critical roles in inflammation, fibrosis development and human cytokine response in HCV-infected HIL mice

To investigate the roles of specific human immune cell populations during HCV infection, we performed antibody-based depletion of human CD4+, CD8 + T cells and CD14+ macrophages in HIL mice prior to HCV infection. The effect of systematic targeted cell depletion was shown (see online supplementary figure S5). Eight weeks after HCV infection, extensive liver scarring with leucocyte infiltration and fibrosis was observed in phosphate buffered saline (PBS)-treated HIL mice (ctrl) (figure $5 \mathrm{~A}$ ). For the HIL mice that were depleted of CD4 + T cells or CD8 + T cells, no obvious liver scarring, leucocyte infiltration or fibrosis were observed after $\mathrm{HCV}$ infection (figure 5A). When HIL mice were depleted of CD14 macrophages, only limited leucocyte infiltration and slight collagen deposition were observed (figure 5A). Serum levels of human IFN $\gamma$ were dramatically reduced in the depletion groups from a mean level of $431.8 \mathrm{pg} / \mathrm{mL}$ in control mice to $1.1 \mathrm{pg} / \mathrm{mL}$ in CD4 T cells-depleted mice, $38.4 \mathrm{pg} / \mathrm{mL}$ in CD8 T cells-depleted mice and $38.8 \mathrm{pg} / \mathrm{mL}$ in macrophage-depleted mice (figure $5 \mathrm{~B}$ ). Serum levels of human IL-6 were reduced from a mean level of
$179.8 \mathrm{pg} / \mathrm{mL}$ in control mice to $0 \mathrm{pg} / \mathrm{mL}$ in CD4 T cellsdepleted mice, $12.1 \mathrm{pg} / \mathrm{mL}$ in CD8 T cells-depleted mice and $3.2 \mathrm{pg} / \mathrm{mL}$ in CD14 macrophage-depleted mice (figure 5C). These results indicate that both $\mathrm{T}$ cells and macrophages play critical roles in the HCV-induced liver pathogenesis. IFN $\gamma$ are known to be mainly produced by $\mathrm{T}$ cells while macrophages are the main sources of IL-6. ${ }^{30-32}$ The depletion of either the human $\mathrm{T}$ cells or macrophages resulted in a drastic reduction of both human IFN $\gamma$ and IL-6 levels, suggesting that there are interplays between the $\mathrm{T}$ cells and macrophages in the immune responses to $\mathrm{HCV}$ infection. However, T cell depletion did not significantly affect the level of HCV RNA in $\mathrm{hEGFR}^{+}$cells isolated from HIL-infected mice (figure 1A), which suggest that successful viral infection alone is not sufficient to cause liver disease and is consistent with the importance of immunemediated pathogenesis in HCV infection. ${ }^{33}$

IFNo-2a treatment blocks the progression of liver disease and antiviral human immune responses in infected HIL mice Human IFN $\alpha-2 \mathrm{a}$ has been used in clinical treatment of HCV-infected patients as it is known to inhibit HCV replication and its subsequent disease progression. ${ }^{34}$ To investigate whether our HIL model can reproduce the therapeutic effect of IFN $\alpha-2 \mathrm{a}$ against $\mathrm{HCV}$ infection, we performed intramuscular injections of recombinant IFN $\alpha-2 \mathrm{a}$ in the HCV-infected HIL mice three times a week. Eight weeks after HCV infection, the PBS-treated HIL mice developed severe liver leucocyte infiltration and 
A

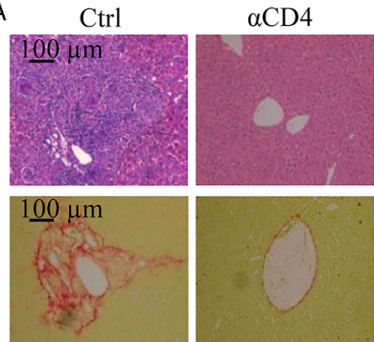

B

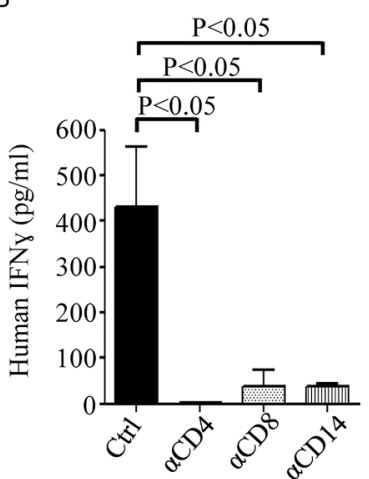

$\alpha \mathrm{CD} 8$

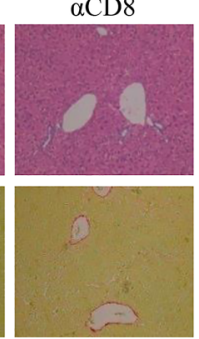

C

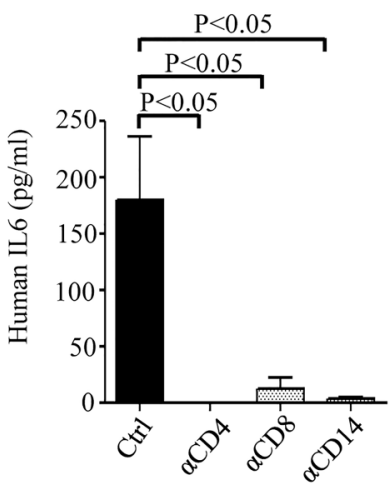

Figure 5 Depletion of human T cells or macrophages in HIL mice significantly reduces inflammation, fibrosis and immune responses caused by HCV infection. Antihuman CD4, CD8 and CD14 antibodies were used to deplete human CD4+, CD8+ T cells and CD14+ macrophage in HIL mice. Livers and sera were harvested from phosphate buffered saline-treated (Ctrl), CD4 ( $\alpha$ CD4), CD8 $(\alpha C D 8)$ or CD14 $(\alpha C D 14)$ antibody-treated HIL mice 8 weeks after HCV infection ( $n=5$ mice per group). (A) Representative liver stains of $H \& E$ to visualise leucocyte infiltration (top row) and stains for Sirius red/Fast green to visualise collagen deposition (bottom row) are shown. Serum levels of human interferon (IFN) $\gamma$ (B) and interleukin (IL)-6 (C) of the HIL mice from the indicated treated groups were determined by ELISA. Data represent mean \pm SEM.

fibrosis, while no leucocyte infiltration or fibrosis was detected in the IFNo-2a-treated group (figure 6A). In the mock-infected PBS-treated or the mock-infected IFN $\alpha$-2-treated HIL mice, there was also no inflammation or fibrosis observed (figure 6A). The production of human IFN $\gamma$ in HCV-infected HIL mice was significantly lower in the IFN $\alpha$-2a-treated group compared with PBS control (figure 6B). However, the serum levels of human IL-6 in the IFN $\alpha$-2a-treated group remained elevated (figure $6 \mathrm{C})$. Notably, the serum levels of human IL-6 also increased slightly in the control group with mock infection and IFN $\alpha-2 \mathrm{a}$ treatment while IFN $\gamma$ remained unelevated (figure 6B, C). The significance of this increase is not clear, but there have been reports that the IFN $\alpha-2 \mathrm{a}$ treatment in $\mathrm{HCV}$-infected patients resulted in an elevation of serum IL-6 level. ${ }^{35}{ }^{36}$ Serum ALT levels in $\mathrm{HCV}$-infected mice were also significantly suppressed after IFN $\alpha$-2a treatment (figure 6D), indicating efficient blocking of liver disease progression. Consistently, detection of HCV RNA performed at 1 and 4 weeks post-IFN $\alpha-2$ a treatment (2 and 5 weeks post-infection, respectively) showed reduction of HCV RNA copy numbers especially at 4 weeks post-IFN $\alpha-2$ a treatment, where $>50 \%$ reduction was observed. An average of 325.6 copy/100 ng of total RNA was detected in the PBS-treated group compared with 140.4 copy/100 ng of total RNA in the IFN $\alpha-2$ a treated group (figure 6E). Hence, our data clearly reproduce the therapeutic effect of the antiviral treatment of IFN $\alpha-2 a$ and strongly suggest that HIL mouse is a useful platform for drug screening and testing.

Clinical HCV strain can induce liver pathogenesis in HIL mice

To investigate whether the HIL mouse model can be used for the study of different genotypes of HCV strains, we inoculated the mice with an HCV clinical strain (CS) of genotype $3 \mathrm{a}$. We were able to observe similar leucocyte infiltration and fibrosis in the HCV CS-infected HIL mice as those infected by J6/JFH-1 (see online supplementary fig. S6A). The immunostaining of human $\mathrm{CD} 45+$ cells confirmed the hepatic infiltration of human leucocytes, which was not observed in the mock-infected mice (see online supplementary figure S6B). These data showed that HIL mice can reproduce liver pathogenesis induced by direct inoculation with clinical isolates from $\mathrm{HCV}$-infected patients.

\section{DISCUSSION}

In most of the published humanised mouse models such as uPA/ SCID or Fah-Rag2- $\gamma$ C-null that were transplanted with human hepatocytes, they were able to support HCV infection but failed to develop liver fibrosis, which may be due to the absence of a functional immune system. ${ }^{9} 11$ The recent AFC8-HSC/Hep Balb/C Rag2- $\gamma \mathrm{C}$-null mouse model that has human immune system and hepatocytes were able to develop fibrosis after HCV infection; however, it requires additional drug treatment to induce mouse hepatocyte apoptosis. ${ }^{15}$ Our HIL mouse model abolishes the need for the induction of mouse hepatocyte apoptosis or surgery, thus has better survival rate upon human cell transplantation. In addition, the NSG mouse used in this work are known to support better human immune cell engraftment and functions than Balb/C Rag2- $\gamma \mathrm{C}$-null mice due to its defective mouse phagocyte activity. ${ }^{37-39}$ In particular in our model, NSG mouse needs only $2 \times 10^{5}$ CD $34+$ fetal liver cells to achieve similar human cell engraftment compared with other models that require 5-10 times more cells. ${ }^{15}$ In addition, mature human hepatocytes were clearly detected in the $\mathrm{hEGFR}^{+}$cells isolated from HIL mice.

In this study, J6/JFH-1 (genotype 2a) and serum from an $\mathrm{HCV}$-infected patient (genotype 3 ) both yielded similar disease outcome in HIL mice. In current model, the level of viral RNA in the blood of the infected mice was too low to be detected. However, a significant level of HCV RNA was detected when $\mathrm{hEGFR}^{+}$cells were enriched from the infected liver. Consistently, HCV protein expression was detected in $\sim 10 \%$ of the human hepatocytes. A similar observation was reported in the AFC8-HSC/Hep model where no serum viraemia was observed and only little viral RNA was detected in the livers from about $50 \%$ of mice at $1-4$ months post-infection. ${ }^{15}$ In contrast, significant viraemia was achieved in the human liver-uPA-SCID or Fah-Rag $2 \mathrm{\gamma C}_{\mathrm{C}}$ null mouse models. ${ }^{9}{ }^{11}$ One possible reason for this difference is that the chimeric level of human hepatocyte, which is derived from fetal hepatic progenitor cells, in HIL mice is $<10 \%$ compared with the $>50 \%$ adult hepatocyte engraftment in the uPA/SCID or Fah-Rag $2 \mathrm{yC}_{\mathrm{C}}$ null mouse models. Notably, in human patients, there are also occult $\mathrm{HCV}$ infection cases where the low level of viral replication is not detectable by commercial kits. ${ }^{40} 41$ Patients with occult HCV viraemia were shown to develop liver inflammation and fibrosis. ${ }^{42}{ }^{43}$ Interestingly, despite the low levels of HCV infection, infected HIL mice consistently developed severe liver damage, fibrosis and cirrhosis. In view of the relatively low reconstitution of human hepatocytes in HIL mice, our results also suggest that infection in only a small proportion of liver cells is sufficient to induce severe disease outcome. In addition to the expression of viral proteins and RNA, the occurrence of 
A
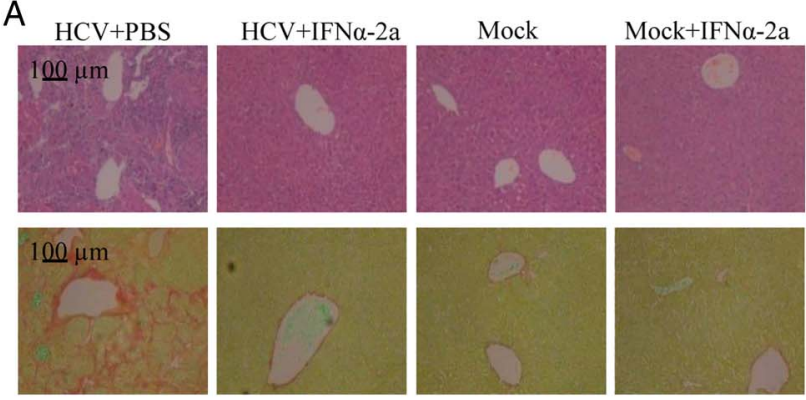

B

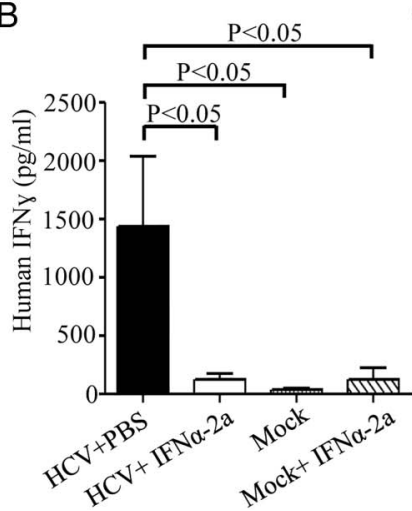

C

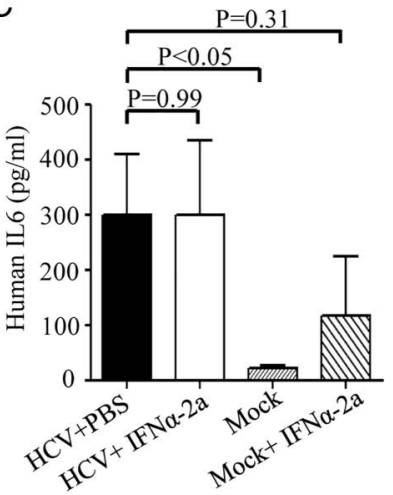

D

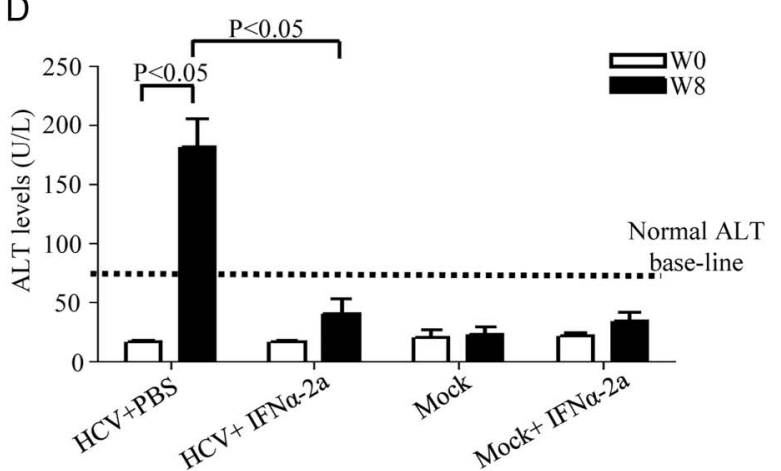

E

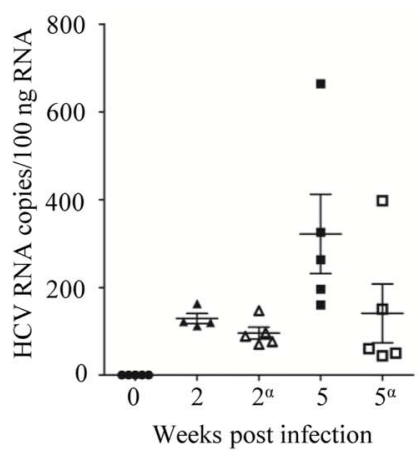

Figure 6 Interferon alpha 2a (IFN $\alpha-2 a)$ treatment prevents disease progression in mice infected with HCV. HIL mice were treated with IFN $\alpha-2 a$ three times a week starting from 1 week post mock-infection or HCV-infection ( $n=5$ mice per group). Livers and sera were harvested at 8 weeks after infection for histology, ELISA and alanine aminotransferase (ALT) measurement. (A) Representative liver stains of H\&E to visualise leucocyte infiltration (top row) and stains for Sirius red/Fast green to visualise collagen deposition (bottom row) are shown. (B) Serum levels of human IFN $\gamma$ were determined by ELISA. (C) Serum levels of human interleukin-6 were determined by ELISA. (D) Serum ALT levels of HIL mice from different treatment groups are represented in the graph. (E) Human epidermal growth factor receptor ${ }^{+}$cells purified from livers of mock-infected, HCV-infected HIL mice treated with phosphate buffered saline (PBS) or IFN $\gamma$-2a (indicated by ${ }^{\alpha}$ ) at 2 and 5 weeks post-infection (1 and 4 weeks post-IFN $\gamma-2 a$ treatment, respectively) and analysed for HCV RNA by RT-PCR ( $n=5$ mice per group). Data represent mean \pm SEM.

robust $\mathrm{HCV}$-specific human $\mathrm{T}$ and $\mathrm{B}$ cell responses and successful antiviral drug treatment also provide independent evidence of HCV infection in HIL mice. However, the degree of chronicity of HCV infection in HIL mice needs further investigation.

The chronic inflammation and immune responses in $\mathrm{HCV}$-infected patients are reported to contribute to the development of the liver disease. ${ }^{44-46}$ HIL mouse successfully recapitulates many features of the disease progression in $\mathrm{HCV}$-infected patients by showing intrahepatic human immune cell infiltration, $\mathrm{HCV}$-specific human immune responses, as well as liver fibrosis and cirrhosis. To our knowledge, this is the first study to report significant serum levels of human cytokine responses to HCV infection in a mouse model. This may be due to the better human cell reconstitution and function in NSG mice. In view of the inflammatory cytokine profiles, notably the cytokines found significantly elevated in HCV-infected HIL mice are the similar cytokine signatures of $\mathrm{HCV}$-infected patients. ${ }^{24-29}$ These results clearly demonstrate that HIL mice are able to produce cytokine and chemokine networks, which closely resemble those described for human infection, to regulate the trafficking and functions of human immune cells responding to HCV infection.

It remains unclear whether the liver diseases caused by HCV are due to the death of infected or healthy cells and how immune system is engaged. Notably, we showed that the inflammation and cell infiltration were initially restricted to human areas in liver but gradually spread and affected non-human areas, and caused massive damage in the whole liver. This probably was due to the production of high levels of human proinflammatory cytokines (eg, IFN $\gamma$ ), which are known to have cytotoxic effects to hepatocytes, resulting in sustained liver damage and eventually in liver cirrhosis. ${ }^{47} 48$ Furthermore, the depletion of either the human $\mathrm{T}$ cells or macrophages resulted in a dramatic decrease in pathology and human cytokine responses, which reveals that $\mathrm{T}$ cells and macrophages are main effector cells in pathology and there are mechanisms regulating their cross-talks. Interestingly, non-HCV-specific T cells appears to be much more abundant than the HCV-specific ones in the liver infiltrate of chronic $\mathrm{HCV}$-infected patients. ${ }^{49}$ Whether or not these unconventional $T$ cells play a role in mediating pathogenesis could be further investigated using the HIL mice. Further investigation on HIL mouse model will help to uncover new mechanisms underlying human specific antiviral immunity and pathogenesis.

Our work demonstrated that HCV strains of two different genotypes can both lead to severe liver diseases in the HIL mouse model. Furthermore, the drug testing of IFN $\alpha-2 \mathrm{a}$ in HIL mice successfully reproduced the therapeutic effects seen in patients. ${ }^{35} 36$ As HCV exist as variants or so-called quasispecies of high complexity and diversity, it has been noticed that drug resistant develops easily and renders the direct-acting antiviral drugs ineffective even in the presence of IFN $\alpha .{ }^{50}$ In the quest to achieve an effective IFN-free regimen, extensive research is now focused on the development of novel drugs like host-targeting agents that target specific host factors essential for HCV replication. Hence, the HIL mouse could be useful in future testing of new drugs or combination of drugs for hepatitis $\mathrm{C}$ treatment. 


\section{Author affiliations}

${ }^{1}$ Institute of Molecular and Cell Biology, Singapore, Singapore

${ }^{2}$ Department of Microbiology, Yong Loo Lin School of Medicine, National University of Singapore, Singapore, Singapore

${ }^{3}$ Department of Obstetrics \& Gynaecology, KK Women's and Children's Hospital, Singapore, Singapore

${ }^{4}$ Department of Pathology and Laboratory Medicine, KK Women's and Children's Hospital, Singapore, Singapore

${ }^{5}$ Division of Microbiology, Kobe University Graduate School of Medicine, Hyogo, Japan

${ }^{6}$ Department of Medicine, Yong Loo Lin School of Medicine, National University of Singapore, Singapore, Singapore

${ }^{7}$ Department of Gastroenterology and Hepatology, National University Health System, Singapore, Singapore

${ }^{8}$ Duke-NUS Graduate Medical School, Singapore, Singapore

${ }^{9}$ Interdisciplinary Research Group in Infectious Diseases, Singapore-Massachusetts Institute of Technology Alliance for Research and Technology, Singapore, Singapore ${ }^{10}$ The Koch Institute for Integrative Cancer Research and Department of Biology, Massachusetts Institute of Technology, Cambridge, Massachusetts, USA

Acknowledgements We thank Antonio Bertoletti (Duke-NUS, Singapore) for giving critical comments and advice and C. M. Rice (Rockefeller University, USA) for providing the pFL-J6/JFH1 and Huh7.5 cells..

Contributors CTK and CWS contributed equally. OC, CTK, Y-JT designed research; CTK, DZ, CWS, ZZ, KSMY, SQT, JJYO, SYT, MHU performed research; EL, SQT, KTEC CHK, SGL, HH, and TCT contributed new reagents/analytic tools; QC, Y-JT, CTK, KSMY, WH and JC analysed data. QC, Y-JT, CTK, WH and JC wrote the paper.

Funding This study was supported by Joint Council Office Development Programme 1334k00082, the Agency for Science, Technology and Research (A*STAR), Singapore, and the Ministry of Education (MOE) of Singapore (AcRF Tier 2, grant no. MOE2012-T2-1-152).

Competing interests None declared.

Patient consent Obtained.

Ethics approval SingHealth Centralised Institutional Review Board B.

Provenance and peer review Not commissioned; externally peer reviewed.

Open Access This is an Open Access article distributed in accordance with the Creative Commons Attribution Non Commercial (CC BY-NC 4.0) license, which permits others to distribute, remix, adapt, build upon this work non-commercially, and license their derivative works on different terms, provided the original work is properly cited and the use is non-commercial. See: http://creativecommons.org/ licenses/by-nc/4.0/

\section{REFERENCES}

1 Shepard CW, Finelli L, Alter MJ. Global epidemiology of hepatitis C virus infection. Lancet Infect Dis 2005:5:558-67.

2 Bruno S, Facciotto C. The natural course of HCV infection and the need for treatment. Ann Hepatol 2008;7:114-19.

3 Bukh J. A critical role for the chimpanzee model in the study of hepatitis C. Hepatology 2004;39:1469-75.

4 Bowen DG, Walker CM. Adaptive immune responses in acute and chronic hepatitis $C$ virus infection. Nature 2005:436:946-52.

5 Legrand N, Ploss A, Balling R, et al. Humanized mice for modeling human infectious disease: challenges, progress, and outlook. Cell Host Microbe 2009;6:5-9.

6 Bukh J. Animal models for the study of hepatitis $C$ virus infection and related liver disease. Gastroenterology 2012;142:1279-1287.e3.

7 Galun E, Burakova T, Ketzinel M, et al. Hepatitis C virus viremia in SCID->BNX mouse chimera. J Infect Dis 1995;172:25-30.

8 Dorner M, Horwitz JA, Robbins JB, et al. A genetically humanized mouse model for hepatitis C virus infection. Nature 2011;474:208-11.

9 Mercer DF, Schiller DE, Elliott JF, et al. Hepatitis C virus replication in mice with chimeric human livers. Nat Med 2001;7:927-33.

10 Dorner M, Horwitz JA, Donovan BM, et al. Completion of the entire hepatitis C virus life cycle in genetically humanized mice. Nature 2013;501:237-41.

11 Bissig KD, Wieland SF, Tran $\mathrm{P}$, et al. Human liver chimeric mice provide a model for hepatitis B and C virus infection and treatment. J Clin Invest 2010;120:924-30.

12 Cooper S, Erickson AL, Adams EJ, et al. Analysis of a successful immune response against hepatitis C virus. Immunity 1999;10:439-49.

13 Shoukry NH, Grakoui A, Houghton M, et al. Memory CD8+ T cells are required for protection from persistent hepatitis C virus infection. J Exp Med 2003:197:1645-55.

14 Ward $\mathrm{S}$, Lauer $\mathrm{G}$, Isba $\mathrm{R}$, et al. Cellular immune responses against hepatitis $\mathrm{C}$ virus: the evidence base 2002. Clin Exp Immunol 2002;128:195-203.
15 Washburn ML, Bility MT, Zhang L, et al. A humanized mouse model to study hepatitis $C$ virus infection, immune response, and liver disease. Gastroenterology 2011;140:1334-44.

16 Bility MT, Cheng L, Zhang Z, et al. Hepatitis B virus infection and immunopathogenesis in a humanized mouse model: induction of human-specific liver fibrosis and M2-like macrophages. PLoS Pathog 2014;10:e1004032.

17 Chen Q, Khoury M, Limmon G, et al. Human fetal hepatic progenitor cells are distinct from, but closely related to, hematopoietic stem/progenitor cells. Stem Cells 2013:31:1160-9.

18 Carpentier A, Tesfaye A, Chu V, et al. Engrafted human stem cell-derived hepatocytes establish an infectious HCV murine model. J Clin Invest 2014; 124:4953-64.

19 Schwartz RE, Fleming HE, Khetani SR, et al. Pluripotent stem cell-derived hepatocyte-like cells. Biotechnol Adv 2014;32:504-13.

20 Schwartz RE, Trehan K, Andrus L, et al. Modeling hepatitis C virus infection using human induced pluripotent stem cells. Proc Natl Acad Sci U S A 2012;109:2544-8.

21 Bataller R, Paik YH, Lindquist JN, et al. Hepatitis C virus core and nonstructural proteins induce fibrogenic effects in hepatic stellate cells. Gastroenterology 2004;126:529-40.

22 Yoshiji H, Kuriyama S, Yoshii J, et al. Tissue inhibitor of metalloproteinases-1 attenuates spontaneous liver fibrosis resolution in the transgenic mouse. Hepatology 2002;36:850-60.

23 Khakoo SI, Soni PN, Savage K, et al. Lymphocyte and macrophage phenotypes in chronic hepatitis $\mathrm{C}$ infection. Correlation with disease activity. Am J Pathol 1997; 150:963-70.

24 Sansonno D, Tucci FA, Troiani L, et al. Increased serum levels of the chemokine CXCL13 and up-regulation of its gene expression are distinctive features of $\mathrm{HCV}$-related cryoglobulinemia and correlate with active cutaneous vasculitis. Blood 2008;112:1620-7.

25 Polyak SJ, Khabar KS, Rezeiq M, et al. Elevated levels of interleukin-8 in serum are associated with hepatitis $C$ virus infection and resistance to interferon therapy. J Virol 2001:75:6209-11.

26 Cicinnati VR, Kang J, Sotiropoulos GC, et al. Altered chemotactic response of myeloid and plasmacytoid dendritic cells from patients with chronic hepatitis C: role of alpha interferon. J Gen Virol 2008:89:1243-53.

27 Nishitsuji $H$, Funami K, Shimizu Y, et al. Hepatitis $C$ virus infection induces inflammatory cytokines and chemokines mediated by the cross talk between hepatocytes and stellate cells. J Virol 2013;87:8169-78.

28 Harvey CE, Post JJ, Palladinetti P, et al. Expression of the chemokine IP-10 (CXCL10) by hepatocytes in chronic hepatitis $C$ virus infection correlates with histological severity and lobular inflammation. J Leukoc Biol 2003;74:360-9.

29 Moura AS, Carmo RA, Teixeira AL, et al. Soluble inflammatory markers as predictors of liver histological changes in patients with chronic hepatitis $C$ virus infection. Eur J Clin Microbiol Infect Dis 2010;29:1153-61.

30 Frucht DM, Fukao T, Bogdan C, et al. IFN-gamma production by antigen-presenting cells: mechanisms emerge. Trends Immunol 2001;22:556-60.

31 Sen GC. Viruses and interferons. Annu Rev Microbiol 2001;55:255-81.

32 Frisdal $E$, Lesnik $P$, Olivier $M$, et al. Interleukin- 6 protects human macrophages from cellular cholesterol accumulation and attenuates the proinflammatory response. J Biol Chem 2011;286:30926-36.

33 Guidotti LG and Chisari FV. Immunobiology and pathogenesis of viral hepatitis. Annu Rev Pathol 2006;1:23-61.

34 Heathcote EJ, Shiffman ML, Cooksley WG, et al. Peginterferon alfa-2a in patients with chronic hepatitis C and cirrhosis. N Engl J Med 2000;343:1673-80.

35 Cotler SJ, Reddy KR, McCone J, et al. An analysis of acute changes in interleukin-6 levels after treatment of hepatitis $C$ with consensus interferon. J Interferon Cytokine Res 2001;21:1011-19.

36 Malaguarnera M, Di Fazio I, Laurino A, et al. Serum interleukin 6 concentrations in chronic hepatitis $C$ patients before and after interferon-alpha treatment. Int J Clin Pharmacol Ther 1997;35:385-8.

37 Ito M, Hiramatsu $\mathrm{H}$, Kobayashi K, et al. NOD/SCID/gamma(c)(null) mouse: an excellent recipient mouse model for engraftment of human cells. Blood 2002:100:3175-82.

38 Brehm MA, Cuthbert A, Yang C, et al. Parameters for establishing humanized mouse models to study human immunity: analysis of human hematopoietic stem cell engraftment in three immunodeficient strains of mice bearing the IL2rgamma (null) mutation. Clin Immunol 2010;135:84-98.

39 Legrand N, Huntington ND, Nagasawa M, et al. Functional CD47/signal regulatory protein alpha (SIRP(alpha)) interaction is required for optimal human T- and natural killer- (NK) cell homeostasis in vivo. Proc Natl Acad Sci U S A 2011;108:13224-9.

40 Bartolome J, Lopez-Alcorocho JM, Castillo I, et al. Ultracentrifugation of serum samples allows detection of hepatitis C virus RNA in patients with occult hepatitis C. J Virol 2007:81:7710-15

41 Dustin LB. Too low to measure, infectious nonetheless. Blood 2012;119:6181-2.

42 Castillo I, Pardo M, Bartolome J, et al. Occult hepatitis C virus infection in patients in whom the etiology of persistently abnormal results of liver-function tests is unknown. J Infect Dis 2004;189:7-14. 
43 De Marco L, Gillio-Tos A, Fiano V, et al. Occult HCV infection: an unexpected finding in a population unselected for hepatic disease. PLOS ONE 2009; 4:e8128.

44 Rehermann B, Nascimbeni M. Immunology of hepatitis B virus and hepatitis C virus infection. Nat Rev Immunol 2005;5:215-29.

45 Dustin LB, Rice CM. Flying under the radar: the immunobiology of hepatitis $C$. Annu Rev Immunol 2007;25:71-99.

46 Grakoui A, Shoukry NH, Woollard DJ, et al. HCV persistence and immune evasion in the absence of memory T cell help. Science 2003;302:659-62.
47 Fallahi P, Ferri C, Ferrari SM, et al. Cytokines and HCV-related disorders. Clin Dev Immunol 2012;2012:468107.

48 Morita $\mathrm{M}$, Watanabe $\mathrm{Y}$, Akaike T. Protective effect of hepatocyte growth factor on interferon-gamma-induced cytotoxicity in mouse hepatocytes. Hepatology 1995;21:1585-93.

49 Klenerman $\mathrm{P}$, Thimme R. T cell responses in hepatitis $\mathrm{C}$ : the good, the bad and the unconventional. Gut 2012;61:1226-34.

50 Pawlotsky JM. Treatment failure and resistance with direct-acting antiviral drugs against hepatitis C virus. Hepatology 2011;53:1742-51. 